\title{
An Approach to Forecast Air Traffic Movements at Capacity-Constrained Airports
}

\author{
Steffen Wenzel ${ }^{*}$ and Katrin Kölker ${ }^{*}$ \\ German Aerospace Center (DLR), 21079 Hamburg, GERMANY \\ Peter Bießlich ${ }^{\dagger}$ \\ Hamburg University of Technology (TUHH), 21079 Hamburg, GERMANY \\ and \\ Klaus Lütjens ${ }^{\ddagger}$ \\ German Aerospace Center (DLR), 21079 Hamburg, GERMANY
}

\begin{abstract}
Due to steadily growing air traffic, airports need a means to evaluate the capability of their infrastructure to handle future air traffic movements. Sound forecasts are needed for fundraising, within lawsuits, and in order to avoid misplanning. The quality of current forecasts is often queried. Hence, this work introduces parts of a tool chain that derives future air traffic movements out of transport scenarios and compares them to the capacity of an airport. Five consecutive models within the chain yield future air traffic movements for one airport considering passenger demand, a forecast of aircraft movements, airline preferences and airport capacity.
\end{abstract}

Nomenclature

$\begin{array}{llll}A N S P & =\text { Air Navigation Service Provider } & G O T & =\text { Gate Occupancy Time } \\ A R R & =\text { Arrival } & G U I & =\text { Graphical User Interface } \\ B W B & =\text { Blended Wing Body } & I F R & =\text { Instrument Flight Rules } \\ C & =\text { Aircraft class (MTOM }=12,500-300,000 \mathrm{lbs}) & M I & =\text { Mix Index } \\ D & =\text { Aircraft class (MTOM }>300,000 \mathrm{lbs}) & \text { MTOM } & =\text { Maximum Take-off Mass } \\ D E P & =\text { Departure } & O D & =\text { Origin - Destination } \\ D L R & =\text { German Aerospace Center } & \text { QSI } & =\text { Quality Service Index } \\ F O A M & =\text { Forecast of Aircreft }\end{array}$

\section{Motivation}

\begin{abstract}
ir traffic will continue to grow with an annual rate of nearly $5 \%$ over the next 20 years ${ }^{1,2}$, which results in increasing loads for airport infrastructure. Additionally, expansions of airports are time-consuming and can only be conducted to a limited extend due to increasing urbanization around airports, limited spatial capability, and limited acceptance by general public. Therefore, well-founded mid- and long-term forecasts (up to 20 years) of air traffic movements at a specific airport and usage of its resources for the purpose of infrastructure extension planning are needed.

In Germany, recent infrastructure projects, like the $4^{\text {th }}$ runway in Frankfurt, the $3^{\text {rd }}$ runway in Munich, or the new airport BER in Berlin, were handled by court. Forecasts are means often used in the legal proceedings to justify the necessity of an infrastructure extension. But the quality and foundation of current forecasts are often questioned during these trials.
\end{abstract}

\footnotetext{
${ }^{*}$ Research Associate, DLR Institute of Air Transportation Systems, Blohmstraße 18, 21079 Hamburg, Germany.

${ }^{\dagger}$ Research Associate, TUHH Institute of Air Transportation Systems, Blohmstraße 18, 21079 Hamburg, Germany.

${ }^{\ddagger}$ Head of Department, DLR Institute of Air Transportation Systems, Blohmstraße 18, 21079 Hamburg, Germany.
} 


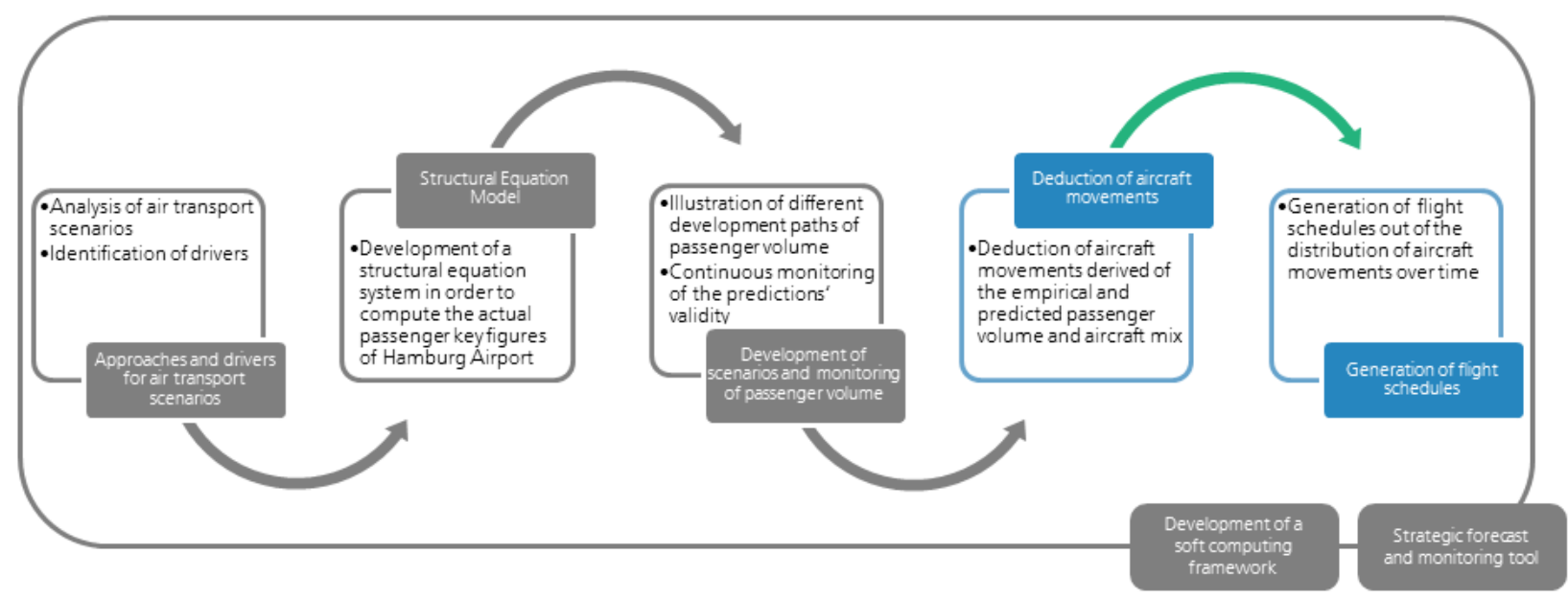

Figure 1. Structure of the project "Validation of Air Transport Scenarios" and scope of this work (colored).

By now, there is no well-founded, fully dynamic model or tool chain for the derivation of air traffic movements at a specific airport based on sound origin-destination (OD) passenger flow forecasts. Within the framework of the project "Validation of Air Transport Scenarios" in the Airport2030 network ${ }^{3}$, a fully-automated tool chain from forecasting origin-destination passenger flows to generating flight schedules for Hamburg Airport using highly sophisticated models is set up step by step (Fig. 1). Furthermore, the tool offers the opportunity to evaluate the impact of new technologies, like new aircraft types (Airbus A380, Blended Wing Body), influencing the capacity of an airport. The tool can easily be applied to other airports. This paper focuses on the deduction of aircraft movements out of OD figures and on the generation of flight schedules (colored in Fig. 1 and detailed in Fig. 2).

Chapter II outlines the methodology of the tool chain. Afterwards, Chapter III presents selected results of the work. Chapter IV states a conclusion of the research conducted.

\section{Methodology}

The model to derive air traffic movements is a top-down approach and comprises five sequential submodels ${ }^{\S}$. They yield a flight plan that can be carried out at a specific airport based on the given demand. The passenger demand, which is the main input data, is given on a monthly OD basis up to the year 2030 and split into different regions. However, the process of generating this data with a regression model ("Structural Equation Model" in Fig. 1) is not scope of this paper and, therefore, will be assumed to be given in the following.

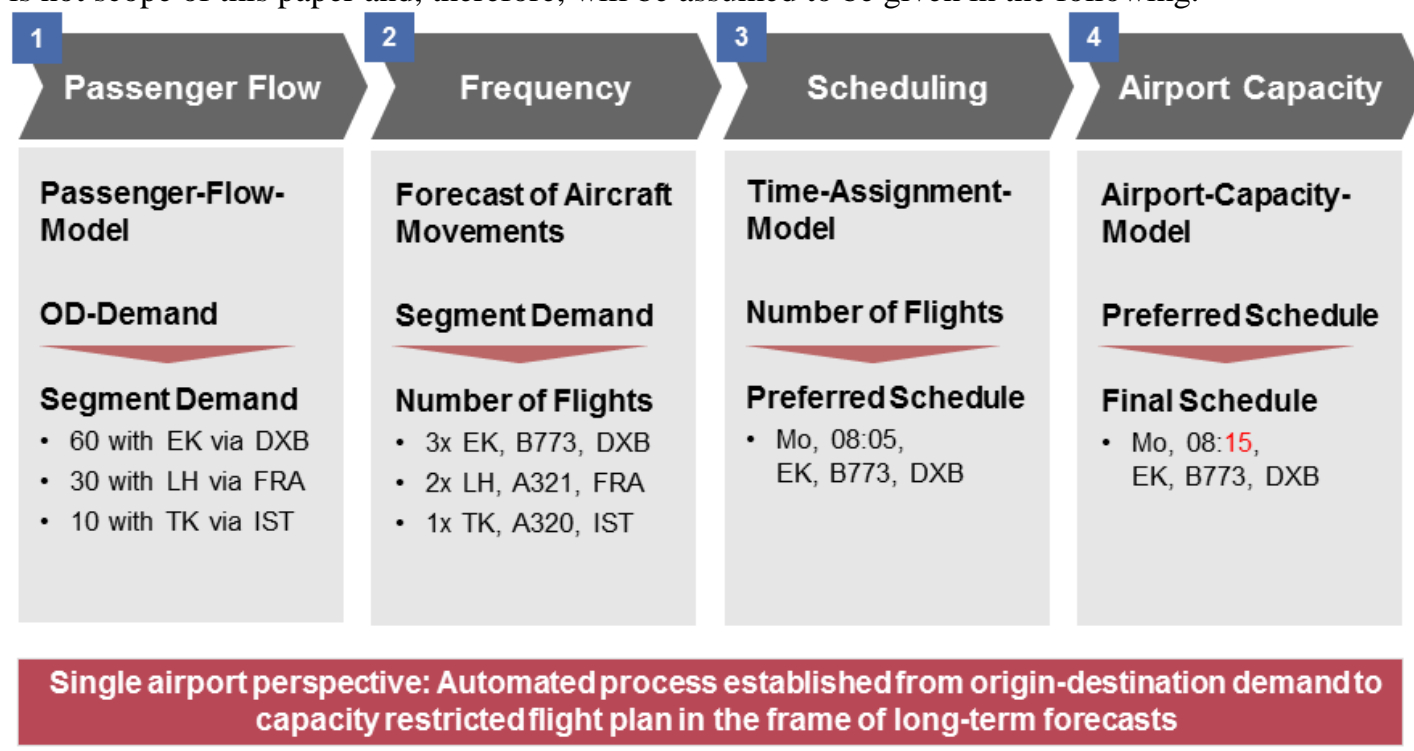

Figure 2. Tool chain from forecasted OD Demand to a Flight Schedule at a Capacity-Constrained Airport.

${ }^{\S}$ In Fig. 2, column 4 "Airport Capacity” comprises the Airport-Capacity-Model as well as the Fitting Algorithm. 


\section{A. Passenger-Flow-Model}

The first submodel, called Passenger-Flow-Model, is a QSI-model (Quality Service Index) considering the passenger preferences with respect to direct or connecting passenger paths. The passenger demand provided by the external regression model is broken down into passenger flows based on flight legs according to their QSI. This approach requires adding new flight legs because future networks comprise an increasing number of legs. Analyses of the network show that if a certain threshold of passenger demand (i.e. connecting passengers) is exceeded on a single OD market, a direct flight becomes attractive for airlines and might be offered. This can be used in order to predict future legs in the network. For that the forecasted passenger demand on every OD market is analyzed and once it exceeds the predefined constant threshold, the leg connecting the airports of the OD market is added to the network and will be served by direct flights from that point of time.

Nevertheless, influencing factors determined by the various characteristics of airlines and airports may result in direct flights on markets with less demand. In order to cancel out these externalities, the ten percent of all markets that have the lowest passenger number are ignored when retrieving the threshold. Subsequently, the threshold is determined as the minimum passenger number of all remaining markets offering a direct flight. To get the future flight network, the current network is expanded by all legs exceeding this threshold.

Additionally, the QSI-model defines the market share for every combination of airlines and transfer airports. This share can be applied to the given passenger demand of different regions. However, as this is a forecast for a specific airport, for all passenger routes only the leg connected to this specific airport is considered regardless of whether the passenger is transferring or using a direct connection.

\section{B. FoAM (Forecast of Aircraft Movements)}

Secondly, a model called FoAM ${ }^{4}$ (Forecast of Aircraft Movements) is used to forecast the fleet mix on every single flight leg. FoAM predicts the trends of air traffic movements and aircraft sizes based on calibrated distribution functions and passenger volume forecasts. Model inputs are statistical data of one reference year. In order to distinguish different categories of flight legs, two criteria are used for identifying them: On the one hand, the distance in $\mathrm{km}$ is used and, on the other hand, the passenger volume per month is taken into account. For every subcategory defined in this manner the distribution of generic aircraft types sorted by their seat capacity is given. For this purpose a value $\alpha$ is predefined indicating the share of flights operated with aircraft types with similar seat capacity. Evaluating schedules and passenger volumes of worldwide legs yields an average share for all aircraft categories. For every flight leg the frequency can be determined by the passenger volume divided by the average passenger number per flight, which is the weighted sum of the product of the mean capacity and the seat load factor for all aircraft categories according to Eq. (1). The sum of the single frequencies of all legs represents the overall frequency at the analyzed airport.

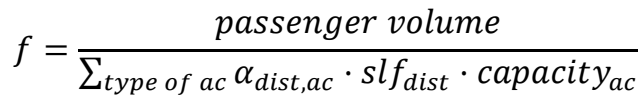

In order to balance and validate the demand for these legs, an additional analysis of historical air traffic movements was carried out. It reveals influencing factors of an airline's choice of specific aircraft. This includes the existing and future fleet of airlines and the mainly operated aircraft at the airport. It is determined with fleet ${ }^{5}$ and historical schedule data. Combined with FoAM, the detailed analysis enables calculating the exact weekly frequency and capacity of every airline starting and landing at the unconstrained airport.

\section{Time-Assignment-Model}

To generate the flight schedule as requested by the airlines, a third model, called Time-Assignment-Model, has been developed. Main assumption is that the choice of the airline for any specific flight is affected by three major aspects. First of all, it considers other flights to or from the same destination at the same day. On the one hand, flights operated by the same airline to the same destination should be spread equally throughout one day. On the other hand, airlines strive for assigning their flights close to flights to the same destination operated by competing airlines in order to skim as much passenger demand as possible. Empirical analyses of schedules confirm this assumption and establish the approach. The third aspect considered is the passenger choices regarding the time of the day. Values from literature are used for implementation ${ }^{6}$. Additionally, an error term $\varepsilon_{t}$ is added in order to capture non deterministic effects as well. Let $f_{t}^{a, o d}$ be a flight from the origin $o$ to the destination $d$ assigned to a slot at time $t$ operated by airline $a$. Using these presumptions, a utility function describing the efficiency of a flight for the airline can be defined as following: 


$$
u\left(f_{t}^{a, o d}\right)=\beta_{1} \cdot \min _{\tilde{t}: \exists f_{\tilde{t}}^{a, o d}}(t-\tilde{t})-\beta_{2} \cdot \min _{\tilde{t}: \exists f_{\tilde{t}}^{a, o d}}(t-\tilde{t})+\text { pax preference }+\varepsilon_{t}
$$

Assigning all flights to slots is implemented by using this utility function as a probability distribution. Those flights with high frequencies are assigned first. In order to maintain a good utility for all flights, this step is continuously repeated. Applying this model leads to a temporary weekly flight schedule.

\section{Airport-Capacity-Model}

The air traffic movements requested by airlines shall be compared to the capacity of the airport of interest. Therefore, the capacity of different infrastructure elements has to be calculated first. Using different well established standard methods ${ }^{7-12}$, airside capacities (runways, taxiways crossing runways, aprons, and gates) are computed dynamically taking into account among others the runway use strategy and traffic mix. Thus, the maximum airside capacity of the airport is determined.

First of all, the declared capacity is used as an indicator for the maximum hourly movements at an airport. The declared capacity depends on the runways in use for take-offs and landings and is published by every country's Airport Coordination?

One approach used to determine airside capacities within the model is the calculation according to the FAA Advisory Circular AC 150/5060-5 “Airport Capacity and Delay"8. The method uses empirical data for given runway configurations in order to provide quick estimates of hourly runway capacity. Besides the runway configuration the Mix Index $(M I)$ is an input variable for the calculation. It is "the relative percentage of operations conducted by each of the four classes of aircraft" and calculated according to Eq. (3). Aircraft class $C$ includes all aircraft with a Maximum Take-Off Mass (MTOM) between 12,500 and 300,000 lbs and $D$ covers all aircraft above 300,000 lbs. ${ }^{8}$

$$
M I=(C+3 D)[\%]
$$

The second procedure used is FAA-RD-74-124 "Techniques for Determining Airport Airside Capacity and Delay"'. It is a graphical method based on empirical regressions. It also uses the MI as declared in Eq. (3). FAARD-74-124 is used to calculate hourly runway capacity, hourly capacity of taxiways crossing active runways, hourly capacity of remote positions, and hourly capacity of gates. The infrastructure element with the lowest capacity is assumed to be equal to the maximum hourly capacity of the airport. Besides the MI and runway configuration used in AC 150/5060-5 this approach also takes into account the length of the runway, the distance of intersections from the threshold, and the position and number of exit taxiways. Hourly capacity of runways is calculated according to Eq. (4), whereby $C^{*}$ is the Hourly Base Capacity, $T$ is the Touch \& Go Factor (which is considered to be 0 for IFR [Instrument Flight Rules] operations) and $E$ is the Exit Factor. The factors are given in tables.

$$
\text { hourly capacity runway }=C^{*} \cdot T \cdot E
$$

Taxiway capacity is only relevant if a taxiway crosses an active runway. For Hamburg Airport, this is only relevant for ARR23/DEP33 and ARR15/DEP05, whereas the numbers describe the direction of the active runway in degrees.

Gate capacity is calculated based on the Hourly Gate Capacity Base $\left(G^{*}\right)$, the number of gates $(N)$, and the Gate Size Factor $(S)$, which represents the amount of gates that are able to accommodate widebody aircraft according to Eq. (5):

$$
\text { hourly capacity gate }=G^{*} \cdot S \cdot N
$$

The gate capacity is also calculated according to ICAO DOC 9184 "Airport Planning Manual, Part 1 - Master Planning"11, which provides a calculation method for determining the number of stands needed to accommodate a given number of aircraft. It can be transposed to Eq. (6) in order to determine the hourly capacity of a given number of gates or remote positions, whereas the Gate Occupancy Time (GOT) is the time an aircraft occupies a gate while taxiing to the gate, during turn-around, and push-back:

$$
\text { hourly capacity gate }=\frac{2 \cdot N}{G O T}
$$


Ashford $^{12}$ introduces a weighted service time in order to consider different classes of aircraft $(i)$ and their respective GOT. Thus, the capacity is calculated as follows extending Eq. (6):

$$
\text { hourly capacity gate }=\frac{2 \cdot N}{\sum_{i} \operatorname{share~}_{i} \cdot G O T_{i}}
$$

Apron capacity is calculated similar to gate capacity.

The user may choose which approach to use for every infrastructure element manually. Otherwise he may choose the most conservative, optimistic or "sophisticated" approach, which means the method with the highest grade of detail in its calculation.

Further analytical methods for determining airport capacity, e.g. based on queuing theory, can easily be implemented in the tool chain.

The user of this tool can change different input parameters to simulate changes in airport infrastructure (e.g. new taxiways, new gates, temporary closure of a runway, etc.) or operations (e.g. shorter turnaround times) and subsequently sees the impact on airport capacity.

\section{E. Fitting Algorithm}

The fitting algorithm simulates the slot allocation negotiations between airport, airline and Air Navigation Service Provider (ANSP) based on the flight schedule generated in the previous step as well as the maximum capacity.

Interviews conducted with several European airlines within the DLR project "P-AIR-FORM - Benefits of Performance Based Airport Management”** showed that airlines prioritize mainly long-haul and feeder flights. Delays for feeder flights are undesirable because connecting passengers may not reach their onward flights. This results in costs for rebooking, eventually compensations and loss of passenger goodwill. Furthermore, feeder flights often operate into coordinated hub airports with restricted slots. These slots need to be used in order to retain them ("grandfather rights"13). Long-haul flights cannot be delayed due to potential curfews at their subsequent destination and mainly due to restrictions on crew working time. Therefore, long-haul flights and flights to hub airports are considered as prioritized by airlines and thus shall receive the desired slot.

Additionally, the fitting algorithm takes into account that non-prioritized flights can only be allocated to a slot that lies within a certain time span around the slot requested by the airline. On the one hand, slots prior to the requested slot are omitted if they are too far away from the requested slot because the aircraft has not yet completed its turnaround. On the other hand, airlines may decide to cancel a flight if the slot is postponed too much because of missing slots at the destination airport, crew limitations or because the succeeding aircraft rotation cannot be completed any more. In this case, it might be favorable for an airline to cancel the flight instead of accepting a late slot. The criterion for slots prior to the requested slot is more restrictive than for late slots. The fitting algorithm also considers night curfews at the airport evaluated.

If the supply of slots lies above the airline demand, all requests will be fulfilled. Otherwise, if more slots are requested than available, the fitting algorithm is initiated. If demand for the slot after the slot examined is below maximum capacity and the slot is not inside the night curfew, a random non-prioritized flight will be moved to the next slot, but only if it has not already been moved too far from the requested slot. If demand for the following slot is already at or above capacity or the following slot is inside the night curfew, the flight will be moved to the previous slot if possible.

The algorithm runs iteratively until equilibrium is found. This may still mean that demand exceeds supply for certain slots. It is, therefore, assumed that all flights requesting slots inside night curfews and above the given demand have to be cancelled.

The result of the fitting algorithm is a flight schedule that can be operated with the given infrastructure. By the use of classification numbers, e.g. the total number of cancelled flights, the capability of the infrastructure to handle the forecasted air traffic movements is evaluated. Several key performance indicators including the skewness and the correlation to other flight plans are used to evaluate the final schedule.

Table 1. Thresholds for passenger demand.

\begin{tabular}{|l|c|}
\hline & yearly threshold (both ways), PAX p.a. \\
\hline short-haul & 14,000 \\
\hline medium-haul & 16,000 \\
\hline long-haul & 65,000 \\
\hline
\end{tabular}

** http://www.dlr.de/lk/en/desktopdefault.aspx/tabid-4469/7258_read-37368/.

American Institute of Aeronautics and Astronautics 


\section{Results}

To retrieve the future passenger flow using a QSI-model, historical passenger information data from the Sabre ADI database $\mathrm{e}^{14}$ are used. A lookup table defining the quality of service index for every airline and transfer airport is generated and made available to the tools. Furthermore, studies concerning the future flight network have been done. This includes defining the number of OD passengers that are required when assuming a direct flight based on analysis of the passenger demand data. The minimum threshold for passenger demand on a single market is given in Table 1. As the European market is highly competitive and, as well, competing with other modes of transportation, the threshold for short-haul distances is very high and close to that for medium-haul distances. The underlying airport is not an international hub, which results in the fact that a direct flight will only be offered when expecting more than 180 passengers daily.

Given the thresholds and the initially defined passenger demand, 28 new airports are selected to join the future network at various points of time. The final future network in 2030 is given in Fig. 3.

After breaking down the demand on the different flight legs, the capacity and frequency is to be assigned to the legs with the help of the model FoAM. Figure 4 shows some results of FoAM for the $401 \mathrm{~km}$ to $800 \mathrm{~km}$ range. Regression curves are derived from the single values of the proportion of flights. The average coefficient of determination of all curves is above 0.93 . Similar curves are retrieved for all other distance categories.

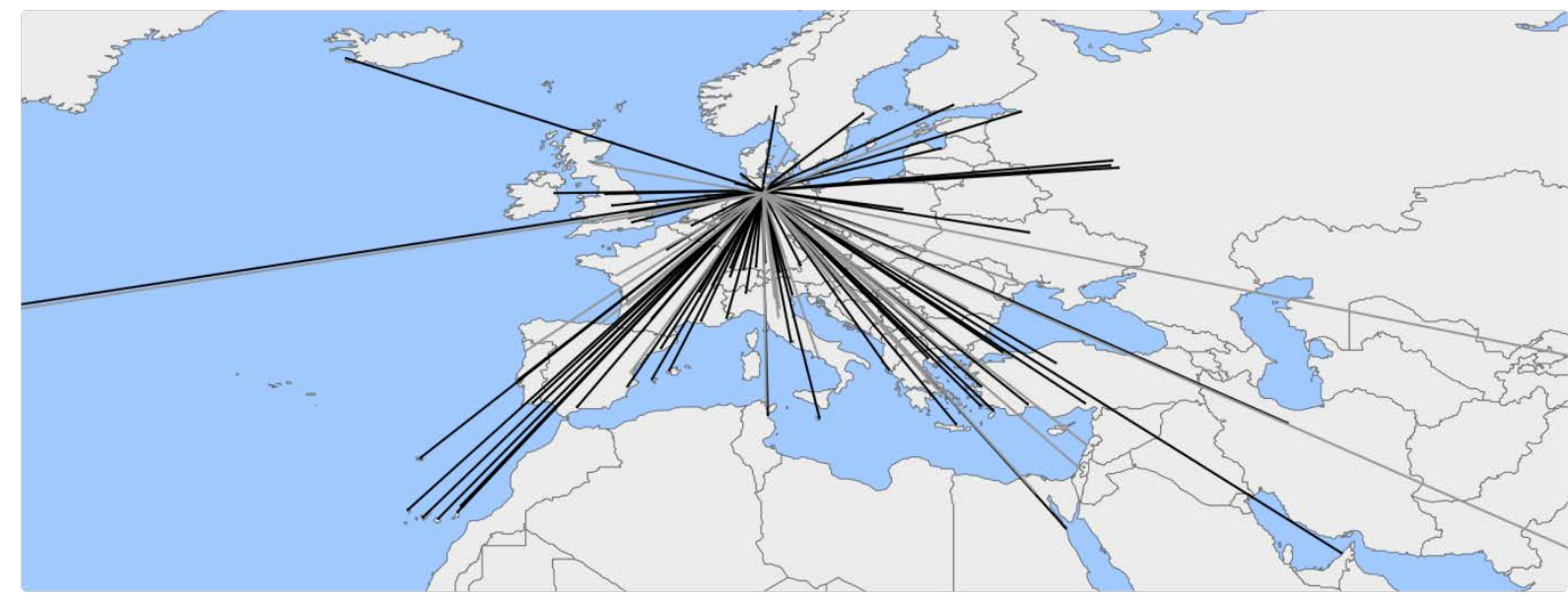

Figure 3. Air Traffic Network for Hamburg 2012 (black) and potential, additional legs for 2030 (grey).

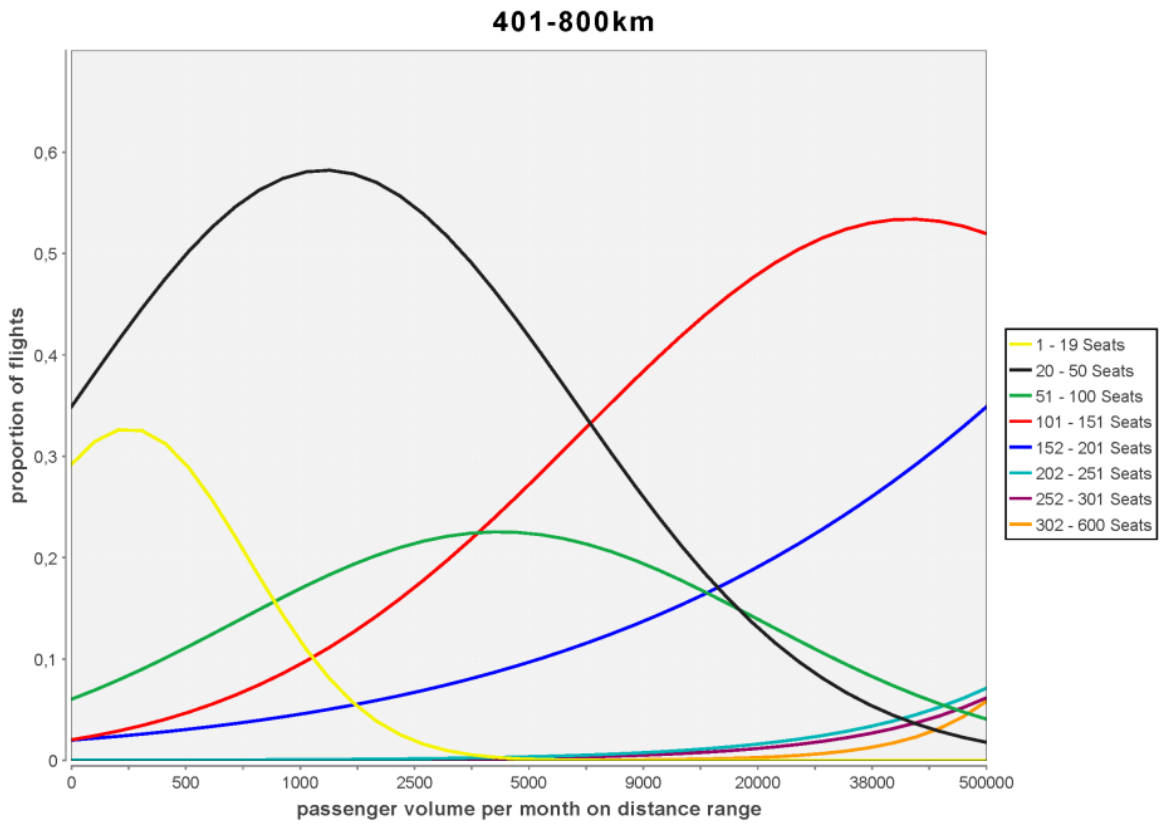

Figure 4. FoAM distribution functions.

6

American Institute of Aeronautics and Astronautics 
Expectedly, small aircraft are used for small passenger volumes and flight leg lengths. The larger the passenger demand the larger the aircraft used.

The distribution functions are very resilient for different years so that it is assumed to have similar functions for future networks. These curves indicate that a global passenger growth of $4.7 \%$ yields a frequency growth of $3.7 \%$.

Furthermore, the seat load factor was assessed by using values of 2012 ranging from $63.9 \%$ for small distances up to $78.8 \%$ for long distances adjusted by a growth of $0.07 \%$ p.a. This value equals the mean growth of the seat load factor from 2003 to 2012. All values are calculated from passenger demand and schedule data. ${ }^{14}$

Airline's preferred choices concerning the aircraft are summed up in another look-up table. With the help of the database Ascend ${ }^{5}$ the aircraft database is

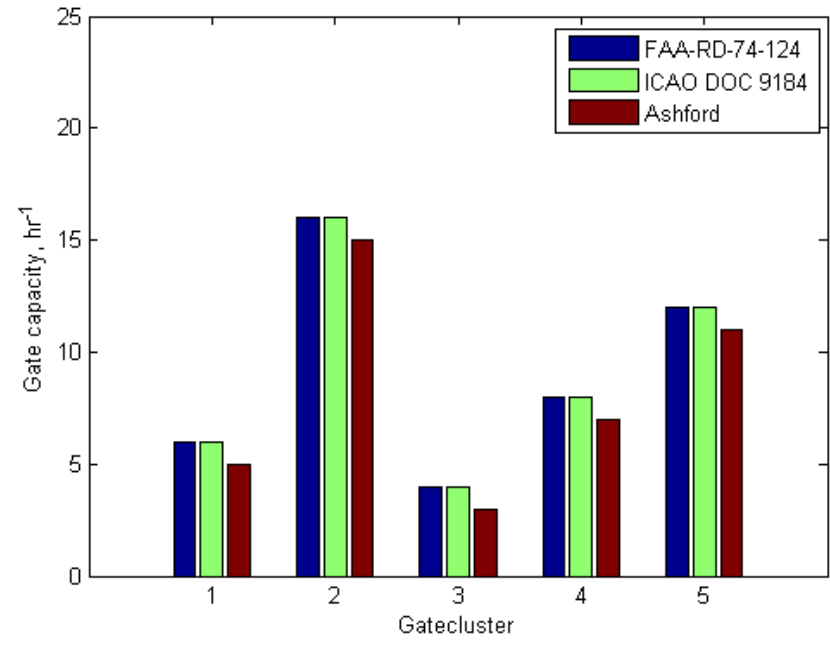

Figure 5. Gate Capacity for existing clusters. extended by future aircraft based on the current orders of the airlines operating at the airport of interest. Combining these specifications with the capacity of the leg leads to the number of departures and arrivals of every airline at the airport on a weekly basis.

The time assignment model is used to allocate a slot for all flights on a weekly basis. To do so, the coefficients of the utility function described in Eq. (2) were calibrated.

Finally, the preliminary flight plan is based on the demand and airline preferences but does not take the capacity into account.

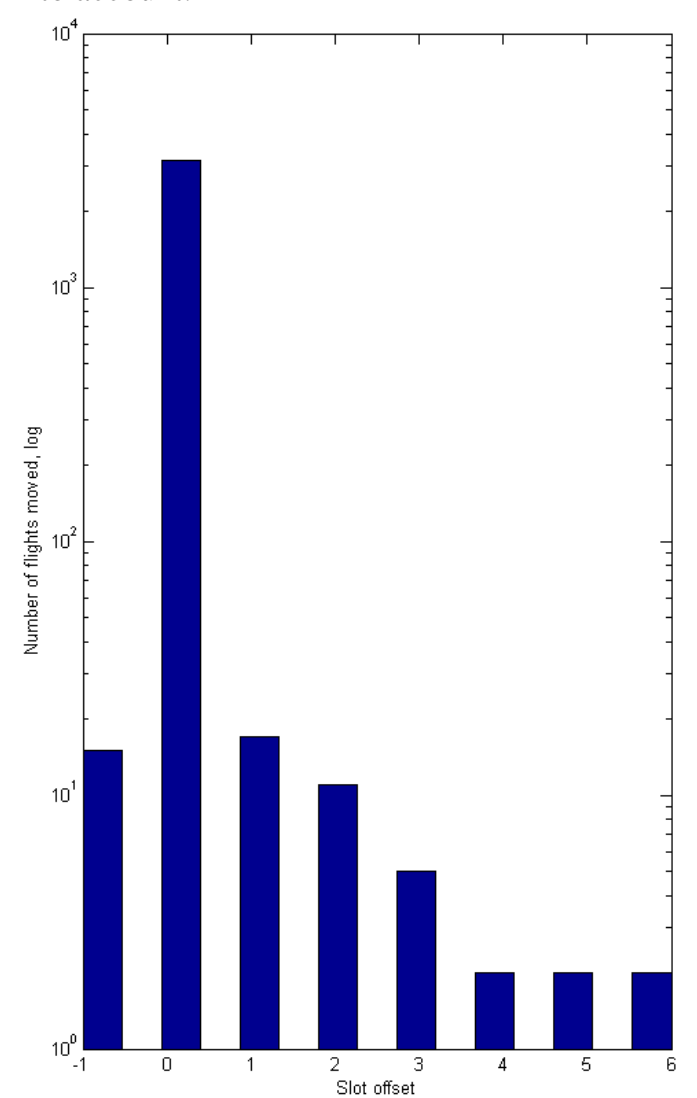

Figure 6. Histogram of flights moved during one week.
As an example of the calculated airport capacity, Fig. 5 shows the gate capacity for different gate clusters and airport capacity calculation methods for a given fleet mix. Every cluster represents 2 to 8 gates at Hamburg Airport. Gates are clustered within the project Airport2030 based on the walking time a passenger needs to reach the gate after security check and the airline or airline alliance using the gate cluster. Thus, it is not necessary to know the exact gate a flight uses, but only its operating airline or typical gate cluster. As a result of the choice of calculation method, which can either be chosen by the user or the tool as described above, there are slightly different results. For Hamburg Airport the results are nearly similar because the main difference between the approaches is the consideration of large aircraft (class $D$ ), which only sum up to $1.44 \%$ of all air traffic movements in the sample flight plan used.

In Fig. 6 the number of flights that were moved for a specific number of slots is shown as a histogram. In this case, aircraft are moved one slot prior and up to six slots after their requested slot. The maximum deviation to the requested slot can be chosen by the user, but 6 slots (i.e. 30 minutes as a slot covers 5 minutes) seem to be a realistic limit.

Figure 7 shows the air traffic movements and runway capacity for one week. The runway capacity changes depending on the runway use strategy. In this example the most restricting calculation method is chosen as the maximum runway capacity.

The deviation of aircraft movements due to capacity constraints can be seen as the difference between the red (unrestricted) and black (capacity-limited) plot. Out of 2016 flights for one week, 167 different flights were moved to another slot in order to achieve equilibrium.

American Institute of Aeronautics and Astronautics 


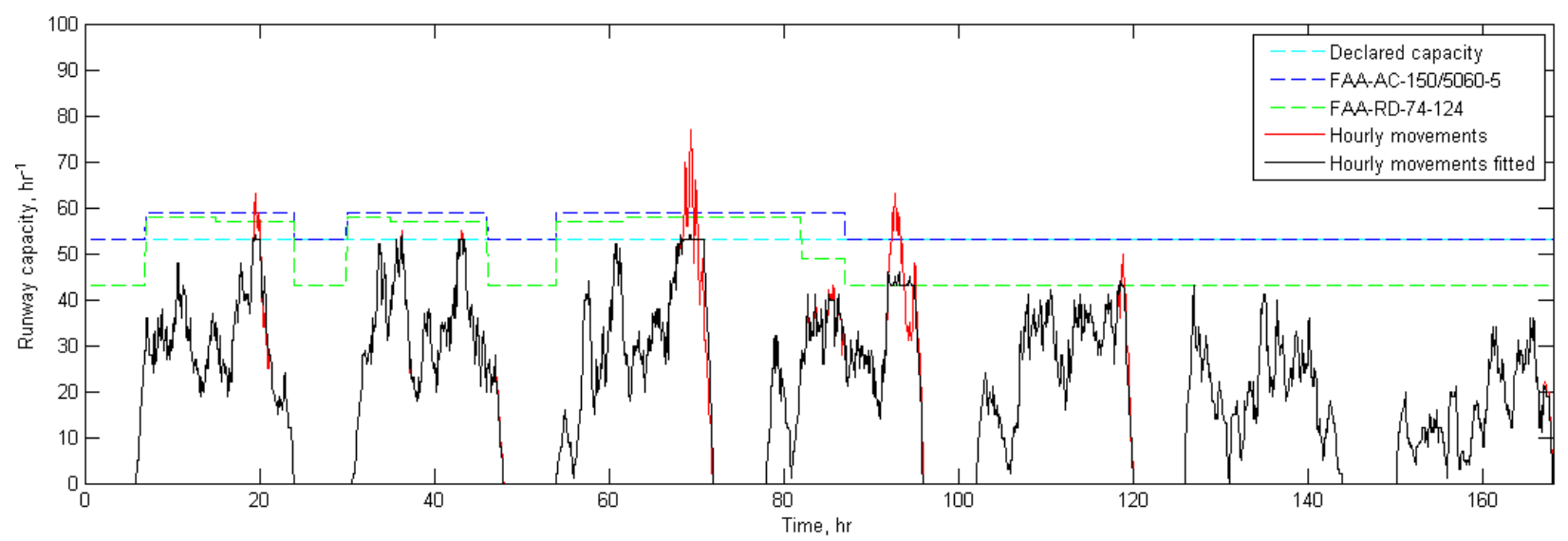

Figure 7. Comparison of unrestricted and capacity-limited ATM for one week and runway capacity.

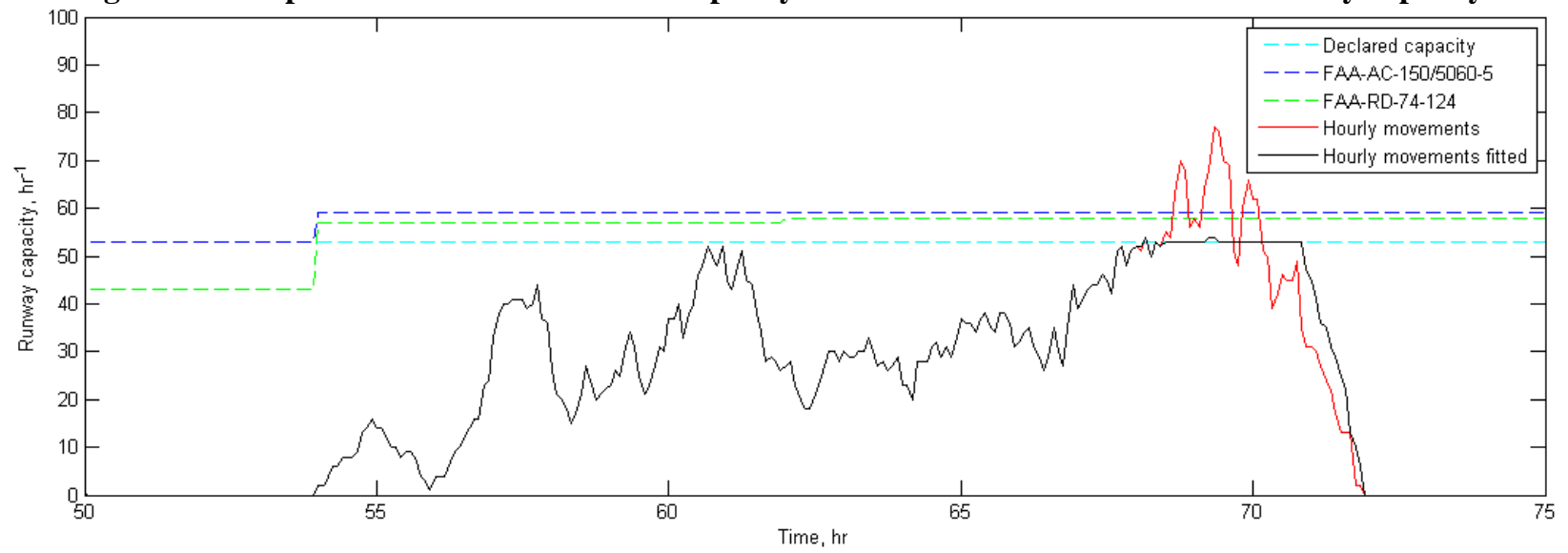

Figure 8. Example of fitting due to runway capacity constraints.

Figure 8 shows a more detailed example of the outcome of the fitting algorithm. If the demand for air traffic movements exceeds the maximum capacity, flights are moved to less occupied slots near the preferred slot based on different assumptions made in the algorithm representing realistic decision making processes of airlines, airport and ANSP.

It can be seen that the choice of the capacity calculation approach has a strong influence on the resulting flight plan. Thus, selecting the most detailed approach is recommended. Using a simulation instead of calculation is assumed to further improve the results.

Assessing the final flight plan requires the definition of four main key performance indicators. First of all, the modes of the minimum time differences of all flights to a flight towards the same destination operated by the same and another airline are evaluated. For the historical flight plan from 2009 to 2012 the modes are 90 minutes for the same airline and five minutes for another. As expected the latter is quite small.

Secondly, the correlation to other flight plans in the same season is used. This index describes the overall distribution of the flights over the whole time horizon. It shows if, for example, peaks and valleys are correlated and on the same point of time. The distribution of flights over one day can also be assessed. Flight plans in winter months are typically spread more over the day meaning that more slots have a higher number of flights assigned whereas the slots in the peak hours have less flights assigned. For a flight plan $f$ let $f(s)$ be the number of flights allocated to slot $s$. The correlation coefficient between two flight plans is defined as:

$$
\operatorname{cor}_{f_{1}, f_{2}}=\sum_{\text {slots }}\left(\frac{\left(f_{1}(s)-\bar{f}_{1}\right)\left(f_{2}(s)-\bar{f}_{2}\right)}{\sqrt{\left(f_{1}(s)-\overline{f_{1}}\right)^{2}\left(f_{2}(s)-\overline{f_{2}}\right)^{2}}}\right)
$$

where $\bar{f}=\frac{1}{\text { number of slots }} \sum_{\text {slots }} f(s)$. 
Table 2. Correlation between historical and reference flight plans.

\begin{tabular}{|l|c|c|}
\hline & $\begin{array}{c}\text { Flight plan } \\
\text { summer 2009-2012 }\end{array}$ & $\begin{array}{c}\text { Flight plan } \\
\text { winter 2009-2012 }\end{array}$ \\
\hline $\begin{array}{l}\text { Reference flight } \\
\text { plan summer }\end{array}$ & 0.74 & 0.48 \\
\hline $\begin{array}{l}\text { Reference flight } \\
\text { plan winter }\end{array}$ & 0.57 & 0.71 \\
\hline
\end{tabular}

A reference summer flight plan and a reference winter flight plan being the mean of all flight plans between 2009 and 2012 are defined to assess the distribution of a flight plan throughout the week. There is a significant difference between the distribution of a summer and a winter flight plan measured in terms of correlation to the reference flight plans (see Table 2).

The fourth key figure analyzed is the skewness, which is defined as follows:

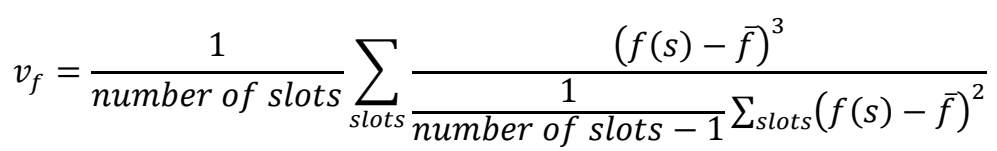

The reference flight plan in the summer has a skewness of 0.95 whereas the winter flight plan has a skewness of 0.76. The skewness is independent from the order of slots and can therefore be used for assessing the overall distribution of flights. A positive skewness indicates that the mode is less than the mean implying a function with a right skew. This means that a positive skewness denotes that more slots having only a few flights assigned exist whereas there are only some slots with lots of flights, which are the peaks of the function. The fact that a winter flight plan has a smaller skewness confirms the assumption that the flights are more equally distributed in winter, because airlines tend to have fewer flights in winter. Thus, airlines have more slack within their aircraft rotations and can avoid peaks. During summer, airlines have tight schedules and have to schedule flights during peaks. A higher skewness in summer indicates a more significant shape of the peak hours. The tool is calibrated to the skewness in order to achieve a distribution of flights that correlate to the given sample flight plans. Thus, observations and knowledge of passenger and airline preferences are considered in the forecast.

\section{Conclusions}

In this paper we presented a highly sophisticated model chain being implemented in one tool to derive a flight plan based on the capacities of the airport and given passenger demand. Validation shows that, even though every submodel uses certain assumptions and simplifications, the tool chain generates generic flight plans that highly match current sample flight plans. Thus, the tool offers airports the opportunity to easily evaluate existing infrastructure capacity and planned infrastructure extensions regarding future air traffic movements. Results can be used in order to justify infrastructure extensions to shareholders, investors and in court. Using an integrated modular tool chain analyzing drivers for air traffic growth, considering airline and passenger preferences, fleet development and airport capacity, the air traffic movements are forecasted. By validation of each submodel a high quality forecast is achieved.

Due to the modularity of the tool chain, every submodel can easily be changed or adapted to prospective developments. The forecast gets even better in future as the input data used for regressions become available for a longer time period.

The influence of new technologies on airport capacity can be evaluated using the tool. For example, the introduction of a large Blended Wing Body (BWB) fosters more direct flights, thus reducing feeder flights, but occupies a gate much longer than a short-range aircraft and reduces runway capacity because of its wake turbulence category.

Different submodels are already utilized and will be used and further developed within other DLR projects, e.g. WeCare $^{\dagger t}$.

${ }^{+\dagger}$ http://www.dlr.de/lk/en/desktopdefault.aspx/tabid-4469/7258_read-37387/. 


\section{References}

${ }^{1}$ Airbus S.A.S., Future Journeys. Global Market Forecast 2013 - 2032, Blagnac Cedex, France, 2013.

${ }^{2}$ Boeing Commercial Airplanes, Current Market Outlook 2013 - 2032, Randy Tinseth, Vice President, Marketing, June 2013, Seattle, WA.

${ }^{3}$ Lütjens, Klaus; Bießlich, Peter; Gollnick, Volker, „Airport2030 - Flughafenforschung im Spitzencluster Luftfahrt,“ Internationales Verkehrswesen, Vol. 66, Nr. 2, May 2014, pp. 84-87.

${ }^{4}$ Kölker, Katrin; Bießlich, Peter; Lütjens, Klaus, FoAM - From Passenger Growth to Aircraft Movements, submitted for publication to: 18th ATRS World Conference of the Air-Transport-Research-Society, Bordeaux, France, 2014.

${ }^{5}$ Ascend, Online Fleet Database. Ascend Worldwide, London, 2014.

${ }^{6}$ Coldren, Gregory M.; Koppelman, Frank S., "Modeling the Competition Among Air-Travel Itinerary Shares: GEV Model Development,” Transportation Research Part A: Policy and Practice, Vol. 39, No. 4, 2005, pp. 345-365.

${ }^{7}$ Airport Coordination Germany, http://www.fhkd.org/, [cited 15 October 2013].

${ }^{8}$ Federal Aviation Administration (FAA), “Airport Capacity and Delay,” Advisory Circular, AC: 150/5060-5, 9-23-83.

${ }^{9}$ Federal Aviation Administration (FAA), “Techniques for Determining Airport Airside Capacity and Delay,” Report No. FAA-RD-74-124, 1974.

${ }^{10}$ Horonjeff, Robert M.; McKelvey, Francis X.; Sproule, William J. and Young, Seth B., Planning \& Design of Airports, $5^{\text {th }}$ revised edition, McGraw-Hill, New York, 2010, Chap. 12.

${ }^{11}$ International Civil Aviation Organization (ICAO), “Airport Planning Manual,” Part 1, Master Planning, Second Edition, 1987, Chap. 7.

${ }^{12}$ Ashford, Norman J.; Mumayiz, Saleh A. and Wright, Paul H., Airport Engineering, Planning, Design, and Development of $21^{\text {st }}$-Century Airports, $4^{\text {th }}$ edition, John Wiley \& Sons, Hoboken, NJ, 2011, Chap. 7.

${ }^{13}$ Council Regulation (EEC) 95/93 of 18 January 1993 on common rules for the allocation of slots at Community airports [1993] OJ L 14/1.

${ }^{14}$ Sabre Airlines Solutions: Airport Data Intelligence (ADI) [online data base], URL: http://www.sabreairlinesolutions.com/home/software_solutions/airports. 